\title{
O desbravador do Oeste e as narrativas do enfrentamento e devastação da natureza na construção da Rodovia Belém- Brasília
}

\section{The conqueror of the West and the narratives of confrontation and devastation of nature in the building of the Belém-Brasilia road}

\author{
Sandro Dutra e Silva ${ }^{1}$
}

Resumo: A conquista geográfica do Oeste foi um ambicioso desafio, em que o domínio da natureza hostil teve um papel fundamental nos discursos oficiais e na literatura relacionada a esse tema. Dessa forma, esse texto tem por objetivo identificar a postura de enfrentamento à natureza presentes nos discursos da Marcha para Oeste e em outros documentos da primeira metade do século $\mathrm{XX}$. O estudo desta documentação tem como finalidade identificar as representações do desbravador do Oeste, por meio da criação da imagem heroica de Bernardo Sayão. $\mathrm{O}$ texto procura se fundamentar nos pressupostos teóricosmetodológicos da História Ambiental, com análise de diferentes fontes e documentos que nos permitem caracterizar as representações da natureza no imaginário social brasileiro das décadas de 1940 a 1950.
Absctract: The geographic conquest of the West was an ambitious challenge, in which the wilderness's dominance had a fundamental role on the official speeches and on the literature related to this topic. As such, this paper aims to identify the confrontational standing of nature presented in March to the West discourses and in other documental sources from the first half of the $20^{\text {th }}$ century. The study of these documents has as its objective to identify the representations of the conqueror of the West, by means of creating a heroic image of Bernardo Sayão. The paper looks to base this theory and methodology on environmental history, by analyzing different sources and documents that permit the characterization of nature's representatives on the Brazilian social imaginative though in the 1940s and 1950s.

\footnotetext{
${ }^{1}$ Doutor em História Social (UnB). Professor Titular do Programa de Pós-Graduação em Sociedade, Tecnologia e Meio do Centro Universitário de Anápolis PPSTMA/UniEVANGELICA; Professor Titular da Universidade Estadual de Goiás (UEG), atuando no Programa de Pós-Graduação em Territórios e Expressões Culturais no Cerrado TECCER/UEG.
} 
Palavras-chave: Natureza, História Keywords: Nature, Environmental Ambiental, Rodovia Belém-Brasília, Marcha para Oeste. History, Belém-Brasília Road, March to the West.

Há, ao longo dos afluentes amazônicos, verdadeiras gargantas vegetais, estreitos e sinuosos desfiladeiros entre paredes de árvores. $\mathrm{O}$ homem aproveitou estas ranhuras aquáticas para avançar para o interior da massa arborescente; não existem outros caminhos além dos rios; tôda a penetração humana, tôda a circulação se efetua por eles...Fora o rio o homem está perdido, soterrado, sem possibilidade de se orientar sob as frondes das árvores, sem pontos de referência.

Deffontaines, 1945.

Em 1965 os geógrafos do Conselho Nacional de Geografia (CNG) Orlando Valverde e Catharina Vergolino Dias, contando com uma equipe de pesquisadores, fruto da parceria entre a Superintendência de Valorização Econômica da Amazônia (SPVEA) e o IBGE, percorreram o longo trecho da Rodovia Belém-Brasília com a finalidade de construir um relatório para a RODOBRÁS, então filiada à SPVEA, no intuito de apresentar um quadro situacional que auxiliasse esses institutos no melhoramento na malha rodoviária. Esse relatório apresentava não apenas um quadro explicativo das condições da estrada, dividindo o trecho percorrido em três seções de abrangência da rodovia (Norte, Central e Sul), como também trazia dados socioeconômicos das áreas, zonas e subzonas de influencia da rodovia (VALVERDE e DIAS, 1967). Algumas dessas referências formam uma fonte privilegiada para o estudo da Historia Ambiental, mas o que me remete ao relatório, como parte da proposta de trabalho a ser apresentada, diz respeito ao conteúdo político-ideológico da imagem da rodovia como um traçado geográfico e simbólico. Não apenas um traço no mapa, mas a conquista de um território historicamente almejado, uma cicatriz na floresta intransponível e o sentido dessa conquista para a sociedade brasileira nas décadas de 1950/60, período de hegemonia dos discursos desenvolvimentistas. A citação de Deffontaines no inicio do texto, retirada da obra de Valverde (1967), retrata a visão da impotência humana frente os desafios da floresta no que diz respeito à circulação e transporte. Impotência essa que alimentava grande obsessão de bandeirantes, 
desbravadores e estadistas que, em diferentes momentos da história brasileira e com objetivos muito diversos entre si, buscavam a integração territorial ou o atendimento a interesses meramente privados, seja por meio da comunicação fluvial, projetos de ferrovias, projetos híbridos ferrofluviais ou outras formas de caminhos e deslocamentos. Em todos esses projetos os desafios se apresentavam gigantescos, devido em parte ao grande território como também pelas condições ambientais.

Nosso objetivo nesse trabalho, que em parte refere-se a relato de experiência em pesquisa de doutoramento (SILVA, 2008) e de um projeto em construção para pós-doutoramento, é perceber os diferentes discursos que evidenciavam uma postura de enfrentamento com a natureza e que posteriormente se configurou em um cenário de devastação ${ }^{2}$ no processo de construção da rodovia Belém-Brasília. Todavia, como projeto de investigação, que contempla uma quantidade significativa de fontes que não puderam ser trabalhadas na pesquisa de doutoramento, tem a finalidade de inserir esse debate nos pressupostos teórico-metodológicos da História Ambiental, ou, numa postura mais modesta, dialogar com esses pressupostos na tentativa de investigar esse objeto e dar a ele um sentido histórico. Assim, alguns recortes são necessários, como a discussão em torno das narrativas de desbravamento e de considerar alguns indícios de devastação, que se concentram em fontes referentes à emblemática figura de Bernardo Sayão, engenheiro agrônomo nomeado pelo Presidente Juscelino para a chefia e execução dos trabalhos da Belém-Brasília e que acabou sendo vitimado por uma árvore em 1959, durante a fase de conclusão da rodovia. A descrição de Sayão como personagem emblemático nesse enredo refere-se ao fato de que sua morte e as circunstâncias pela qual veio a falecer constituem um pano de fundo discursivo privilegiado para nossa análise.

Este texto procura apresentar a maneira como as questões ambientais apareciam nos discursos de colonização e expansão para o Oeste brasileiro nas décadas de 1940 e 1950 e observar a relação existente

\footnotetext{
${ }^{2} \mathrm{O}$ uso desses conceitos e categorias, importantes para a compreensão da relação entre homem e natureza e consequentemente para os estudos da História Ambiental parecem diluídos no decorrer do texto, principalmente o conceito de enfrentamento, uma categoria típica dos discursos do desbravador das florestas em Cassiano Ricardo (1959). Já o termo devastação surge no sentido de apresentar os indícios da relação entre o homem e natureza no sentido de apontamento dos efeitos provocados por essa interação no que se refere a mudanças no ambiente (WORSTER, 2003; MARTINEZ, 2006).
} 
entre as políticas desenvolvimentistas e percepção da natureza como impedimento ao progresso. Esses discursos apresentavam a natureza como inimiga do progresso e que, portanto, a relação estabelecida incentivava o enfrentamento. Diferente da abordagem de Pádua (2004), cujo trabalho buscava identificar a forma como a destruição do ambiente natural no Brasil durante os séculos XVIII e XIX incitava uma reflexão profunda e até mesmo pioneira no contexto do debate ambiental, mesmo que minoritária, nossa abordagem segue o caminho inverso, talvez mais até mais óbvio no que se refere à nossa tradição de devastação e enfrentamento em relação ao ambiente natural. No trabalho de Pádua (2004) a destruição ambiental, a partir das fontes analisadas, não representava um "preço do progresso", mas sim um "preço do atraso", na medida em que, fundamentados numa tradição iluminista sobre a "sobrevivência e o destino da comunidade política", defendiam a preservação do ambiente natural na defesa dos interesses nacionais. Assim, os valores da natureza não eram mensurados por sua importância estética, ética ou espiritual, mas pelo correto aproveitamentos dos recursos que ressaltavam os conceitos de progresso tecnológicos e práticas sociais científicas, ressaltando o caráter econômico e político do mundo natural. Para o autor a crítica ambiental, encontrada no pensamento político brasileiro da época, apresentava os recursos naturais como elemento fundamental para o progresso do Brasil, sendo que a "destruição e o desperdício dos mesmos eram considerados uma espécie de crime histórico, que deveria ser duramente combatido" (PÁDUA, 2004: 13).

Nossa abordagem, inserida no contexto desenvolvimentista brasileiro no século XX procura mostrar como a tradição de enfrentamento da natureza era evidenciada em nome do progresso. Pactuo com Pádua (2004) o conceito de tradição como retomada de temas e de preocupações e não como uma doutrina básica. Ao mesmo tempo, essa tradição não buscou fundamentação num conjunto de reflexões sobre a natureza (PÁDUA, 2004; FRANCO et DRUMMOND, 2009) mas numa fonte muito utilizada como recurso retórico do período da Era Vargas (1930-1945) e do governo de Juscelino Kubistchek (1956-1960) que foi a Marcha para Oeste de Cassiano Ricardo (1959) com todos os elementos ideológicos que reforçavam o enfrentamento com o mundo natural em nome do progresso. Além da obra de Ricardo (1959) procuramos identificar nos discursos em alusão ao falecimento de Bernardo Sayão, proferidos pelo campo político (Presidência da República e do Senado Federal) e pela imprensa brasileira e sua repercussão na época. Esses discursos foram elaborados em consonância às políticas governamentais de ocupação das fronteiras territoriais brasileiras e a narrativa da Marcha e do destino manifesto bandeirante (RICARDO, 
1959). Os discursos foram tratados neste texto como conteúdo simbólico que procurava justificar as ações governamentais no enfrentamento à natureza, bem como identificar nessas narrativas os mitos e representações que a consideravam inimiga do progresso.

\section{O projeto rodoviário e ocupação da Amazônia}

O período colonial evidenciava a fragilidade humana na conquista da região amazônica e grande desafio dessa empreitada. No século XVIII as divisões geopolíticas do território brasileiro promovidas pelo Marques de Pombal evidenciam o isolamento efetivo entre Norte e Sul. Tentativas e alternativas para a abertura e ligação dessas regiões por rotas interioranas esbarravam nos obstáculos naturais, seja pelo caminho fluvial ou pela ferrovia no século XIX. Uma alternativa apresentada vislumbrava um sistema ferro-fluvial, mas os altos custos inviabilizavam o investimento que na época parecia não justificar o financiamento desse projeto. Entre 1941 a 1944, como administrador da Colônia Agrícola Nacional de Goiás, Bernardo Sayão realizou as obras da Rodovia Transbrasiliana que ligava a cidade de Anápolis com a região Médio-Norte de Goiás chegando até a cidade de Uruaçu, banhada pelo Rio Maranhão, afluente do Tocantins. Em 1935 a ferrovia chegava à Anápolis, ligando a região Central de Goiás com litoral brasileiro. Em 1947 o Plano Nacional de Transporte buscava conjugar a viação rodoviária, ferroviária e fluvial na ligação entre Anápolis-Belém. Nesse mesmo ano um projeto foi apresentado no Congresso Nacional pelo deputado goiano Jales Machado e previa a incorporação dos três sistemas de viação no trajeto Anápolis-Belém (VALVERDE, 1967).

No governo de Presidente Juscelino a legislação que tratava da transferência da capital e a construção de Brasília estabelecia a construção de uma rede de rodovias com as diferentes regiões do Brasil como forma de consolidar sua localização no Planalto Central. O nome da rodovia BelémBrasília situa-se no contexto desenvolvimentista do governo JK por meio da disposição da Lei $\mathrm{n}^{\circ} 2.975$ de 27 de novembro de 1956 que abandonava o projeto rodo-fluviante por meio do projeto rodoviário. $\mathrm{O}$ decreto $\mathrm{n}^{\circ} 43.710$ de 15 de maio de 1958 criava a Comissão Executiva da Rodovia BelémBrasilia (RODOBRÁS), colocando no seu comando o engenheiro Bernardo Sayão (VALVERDE, 1967). 
Segundo Valverde (1967) os fatores naturais tiveram papel essencial nas técnicas do traçado e construção da rodovia, sendo que no trecho entre Uruaçu e Imperatriz, de predomínio de vegetação de cerrado, procurou seguir o caminho dos rios, alongando o trajeto percorrido, mas barateando a construção pela redução de obras de intervenção. Sayão com apoio da aeronáutica sobrevoou a região e adaptou um sistema fotográfico para

registrar o traçado da rodovia, servindo de orientação topográfica para o maquinário pesado na abertura da estrada. De Imperatriz ao Vale do Guamá no Pará o trabalho foi realizado por uma equipe de topógrafos e mateiros que abriam clareiras que eram seguidas pelas máquinas moto-niveladoras. Foi a parte mais árdua da construção com duas frentes de trabalho, uma iniciada na parte Norte e outra a partir de Imperatriz no Sul. Nessa frente de trabalho, em Acailândia no Maranhão em janeiro de 1959, Bernardo Sayão foi atingido por uma árvore e faleceu. Os trabalhos se estenderam até 1960, quando o próprio Presidente Juscelino, em ato simbólico, derruba o último jatobá, marcando a conclusão da rodovia (VALVERDE, 1967). Considerando a carga de elementos históricos que evidenciam a relação entre homem e natureza num cenário de enfrentamento e devastação que objetivamos tratar dessa temática nos pressupostos da História Ambiental.

\section{O enfrentamento: natureza e desbravador nas narrativas da Marcha para Oeste.}

A obra de Ricardo (1959), publicada em 1942, servia como orientação fundamental para as políticas de expansão de fronteiras durante o Estado Novo (1937-1945) na medida em que justificava os deslocamentos territoriais baseando-se no enfrentamento do desbravador (homem em marcha) e a natureza. Seus argumentos procuravam reforçar que em nossas raízes culturais, o movimento bandeirante teve papel fundamental por representar a vocação natural de nossas instituições sociais, apresentando a Bandeira como "gênese do Estado brasileiro" pela força dinamizadora presente nos deslocamentos, na ocupação territorial, na fundação de cidades e nas conquistas geográficas do país.

Além de apresentar a função política e social da Bandeira, elaborava as características que constituíam o ethos bandeirante, descrevendo os referenciais psicossociais geradores dessa instituição cercada pelo universo do fantástico e do fabuloso, cujas lendas e mitos tinham uma função motriz na empreitada bandeirante. $\mathrm{O}$ próprio bandeirante recriava esse universo de 
fábulas e lendas como elemento motivador para a expansão geográfica e, ao mesmo tempo, tornava-se parte do enredo fabuloso, na medida em que o deslocamento reconstituía o mito no imaginário da Bandeira. Os mitos ligados às representações de riqueza desenvolveram sentimentos psicomotores que interferiam no comportamento da Bandeira (grupo em marcha), proporcionando o enredo psicossocial para o mito. Ricardo (1959) defende que nem mesmo os mitos inibidores da natureza foram capazes de impedir a força que o sertão enigmático exercia na imaginação do bandeirante, num cenário em que tudo respirava lenda. Esse universo mítico do "mundo primitivo e fantasmagórico" da Bandeira era alimentado pela "geografia fabulosa, o ouro inseparável da lenda, as viagens pelo desconhecido" (RICARDO, 1959: 106). Ao descrever o bandeirante e sua relação com o universo fabuloso e religioso, o autor procurava estabelecer uma distinção entre o místico (que se fundamenta no sobrenatural religioso) e o animista (fundamentado na crença aos mitos), afirmando ter o bandeirante muito mais de animista do que de místico. Os mitos conduziam e impulsionavam a marcha, e as devoções religiosas limitavam a acompanhá-la: "mitos na frente, santos atrás - e lá se vai a bandeira" (RICARDO, 1959: 118). No conflito entre os mitos inibidores e aqueles que convidavam às entradas, dando acesso ao sertão, foram vencedores os segundos. A narrativa procurava reforçar a importância dos mitos, considerando os resultados práticos gerados por eles - "não fossem esses mitos, como os de serra verde, da lagoa dourada, etc., e o Brasil não seria o que é hoje, em sua grandeza geográfica." (RICARDO, 1959: 119) - ao mesmo tempo em que buscava valorizar o caráter mítico do bandeirante.

Ao tratar da função do mito da bandeira e a sua contribuição para a formação das fronteiras geográficas do Brasil, percebe-se a intenção de construir a figura do bandeirante como mais um elemento mítico. $\mathrm{O}$ caráter mítico, entretanto, que renascia no século XX, não buscava dar sentido fabuloso para o neobandeirismo, mas procurava vincular essa empreitada às raízes da bandeira histórica. Nesse sentido, o mito ganhava novas feições, baseando-se, agora, não mais nas narrativas fabulosas, mas nas atitudes que fugiam ao regular e ao ordinário. Na tentativa de qualificar essas atitudes uma nova definição de bandeirante nascia, ou mesmo um espírito bandeirante formava-se como referencial a uma prática valorizada como superior ao homem comum. Se a linguagem fabulosa era vista como fundamental para a explicação mítica da bandeira e das ações dos 
bandeirantes históricos, era necessário identificar nos novos bandeirantes atitudes que permitissem qualificar o espírito da Bandeira. A narrativa de Ricardo (1959) prontificava-se a realizar essa tarefa no campo cultural, justificando a apropriação dos discursos ideológicos do Estado Nacional para a colonização do Oeste, ao mesmo tempo em que qualificava aqueles que imigravam como dotados de desbravadora brasilidade. O programa desenvolvimentista de $\mathrm{JK}$ fez uso desses novos recursos aliados à mudança da capital para o Planalto Central e no chamado aos brasileiros

para o deslocamento.

A narrativa da marcha considerava que, no século XIX, o espírito bandeirante parecia quase extinto aos olhos do povo brasileiro. Porém, a despeito dessa visão, afirmava que o bandeirismo resistia e cumpria seu papel histórico naquele tempo na figura do "bandeirante desbravador". Chegava a afirmar que esse tipo social foi um traço dos paulistas, mas que posteriormente foi reconhecido no brasileiro em geral as características que o incluem nessa tipologia. $\mathrm{O}$ autor apresentava as novas bandeiras dos séculos XIX e XX, identificando os aspectos principais do bandeirismo em seis momentos distintos, em que persistia o espírito desbravador: nas chamadas zonas pioneiras; nas migrações internas; na conquista do último Oeste; na demarcação e posse efetiva das regiões conquistadas com sentido político-cultural; e na Fundação Brasil Central, que previa a mudança da capital da República para o planalto goiano (RICARDO, 1959).

Personagens históricos do final do século XIX e da primeira metade do século XX foram destacados pelo autor, como forma de evidenciar para as novas gerações que o espírito bandeirante ainda estava vívido na sociedade da época, como Marechal Cândido Rondon. Ele apresentava esses personagens como "novos bandeirantes", cada um a seu modo, com a intenção de mostrar que o bandeirismo não era apenas uma narrativa fabulosa da história mas um movimento vital para a sociedade brasileira, e era importante que essa sociedade percebesse esse fato.

O tipo desbravador dominava o enredo da obra, uma vez que, composta de dois volumes, procurava abarcar desde o bandeirismo histórico do período colonial até o neobandeirismo do século XX. O elemento mítico da bandeira fazia referências a esse tipo de bandeirismo, apresentando o desbravador como o "enfrentador de mitos". Ao mesmo tempo em que constituía uma imagem de enfrentamento, tornava a atividade de bandeirar, por sua vez, num outro mito, em que elementos como coragem, fé e determinação qualificavam o desbravador. $\mathrm{O}$ objetivo final - seja a riqueza 
no bandeirismo histórico ou o estabelecimento e ocupação das fronteiras nacionais do neobandeirismo - fazia com que os mitos da inibição, principalmente da natureza, fossem derrotados pelos mitos da conquista. $\mathrm{O}$ desbravador era portanto "aquele que enfrentava a natureza", pois, além de enfrentar com coragem as alegorias fabulosas dos mitos da inibição, lutava com as dificuldades da marcha no cenário natural: "luta com a geografia, com a floresta, com os rios encachoeirados, com os igarapés, com as nascentes ocultas do labirinto amazônico - e ainda com os índios, doenças, feras e monstros na fixação da fronteira" (RICARDO, 1959: 321).

Além dessas características, o desbravador incorporava o "destino histórico" que lhe reservava a condição de mito. $\mathrm{O}$ autor reforçava o caráter mítico do desbravador por meio dos caminhos abertos para o interior do país e na fundação de cidades. A sua observação era que muito já havia sido feito por obra do bandeirismo, como destaque para a conquista territorial brasileira. Porém, afirmava que esse vasto território carecia, ainda, ser ocupado e a atividade bandeirante era fundamental naquele momento histórico em que as políticas federais para imigração e colonização das fronteiras cumpriam tal destino. A força simbólica da marcha estava no caráter intencional e extensional do discurso, que qualificava a todos os brasileiros que atendiam a seu chamado como verdadeiros bandeirantes: "Todo brasileiro que abre caminhos novos é, hoje, um bandeirante. [...] o papel da bandeira é, ainda, uma imposição da vida a que o brasileiro não poderá fugir, para se realizar. [...] Enquanto se puder, no Brasil, abrir uma estrada ou fundar uma cidade. (RICARDO, 1959: 391)

A narrativa da marcha buscava incluir as demais formas de bandeirar no ethos paulista, mas ficava evidente o caráter mítico que o desbravador teve nessa representação, visto simbolicamente como agente histórico da grandeza territorial. No campo político essa narrativa incentivava os deslocamentos para o Oeste e a consequente ocupação do hinterland brasileiro. A postura de enfrentamento era incentivada, reforçando o ato de desbravar como heróico e colocando a natureza como mito a ser combatido. $\mathrm{O}$ desbravador enfrentava e vencia esses mitos, em nome dos interesses nacionais e da brasilidade, termo muito usado pelos modernistas.

A utilização de Bernardo Sayão como representante do ethos bandeirante desbravador tem como justificativa a utilização desse personagem como ícone das políticas de integração nacional e dos programas desenvolvimentistas do governo de Juscelino (1956-1960). É 
importante ressaltar que não existe em nenhum momento no texto de Ricardo (1959) menção a Bernardo Sayão. A edição de 1959, ano da morte de Sayão, teve o acréscimo de dois novos capítulos que tratavam da construção de Brasília, não fazia referências ao engenheiro, mas ao Presidente Juscelino, representante do neobandeirismo. Porém, as imagens arquetípicas do herói bandeirante em Bernardo Sayão foram extraídas de discursos oficiais, notas da imprensa brasileira e estrangeira da época e em narrativas orais, mantendo a mesma analogia com o texto de Ricardo. A forma emblemática de sua morte na construção da rodovia Belém-Brasília serviu como enredo para a justificação das políticas de expansão territorial e

de desbravamento em nome do desenvolvimento.

Bernardo Sayão trabalhou em diferentes órgãos do Ministério da Agricultura na antiga capital federal na década de 1930, logo após a conclusão do curso de agronomia. No início da década de 1940 foi nomeado por Getulio Vargas para coordenar os trabalhos de implantação da primeira Colônia Agrícola Nacional em Goiás (CANG), ficando na administração até 1950. Em 1954 foi eleito vice-governador por Goiás e no ano seguinte coordenou a construção de um campo de pouso para aeronaves na região que receberia a visita do Marechal José Pessoa, presidente da Comissão de Localização da Nova Capital. Em 1956 foi nomeado diretor da Companhia Urbanizadora da Nova Capital do Brasil (NOVACAP), coordenando uma série de obras em Brasília. Em 1958, dentro das atribuições da NOVACAP, foi nomeado por Juscelino para a construção da rodovia que ligaria a nova capital à cidade de Belém, no Estado do Pará, numa extensão de 2.169 quilômetros. Em 15 de Janeiro de 1959 morreu atingido por uma árvore que caiu sobre seu acampamento em Açailândia (MA), sendo velado e sepultado em Brasília (ArPDF, 2004).

Uma imagem se constitui não apenas pela teatralização de um papel que se impõe, mas na construção de cenas individuais que se somam aos enredos coletivos (BURKE, 1994). Certa ironia no enredo envolve a constituição do mito, que de desbravador foi vítima da vingança da natureza. Esse enredo em nossos dias poderia ter outra conotação, mas a forma como foi apropriada na época reforçava o caráter desbravador e de enfrentamento com a natureza. Ao invés de ser vista como as conseqüências de descaso com a natureza e a fatalidade da morte ser apresentada como advertência as narrativas reforçavam a necessidade de ampliar o enfrentamento com a natureza e o engenheiro recebia as glórias do bandeirismo.

A imprensa carioca enfatizou que esse seria o primeiro 
sepultamento ilustre na futura capital e que o "Engenheiro Bernardo Sayão era o general de uma batalha terrível. Morreu em combate contra a floresta, abrindo terreno para a Estrada Brasília- Pará" (MÜLLER, 1959: 50). Outros relatos memorialistas procuravam descrever os momentos biográficos que antecederam a formação do homem público, apresentando certas características do personagem, como o carisma, entusiasmo, espírito aventureiro e a energia como que ele sempre investia em suas atividades, estabelecendo uma relação com o bandeirante da Marcha. Alguns artigos da imprensa carioca buscavam relacionar as dimensões do homem comum ao herói bandeirante: ia além do desbravador, do mateiro que doma a floresta, funda curral e fazenda e passa a cuidar do futuro dos seus. [...]. Abria mato a facão, atravessava rio a nado, plantava um estabelecimento e ficava à frente dêle como chefe, rei, juiz (JORNAL CORREIO DA MANHÃ, 1959: $45)$.

A tipologia do desbravador indicava que esse arquetípico bandeirante era classificado como animista (fundamentado em mitos) e seu ethos inspirava a constituição de um espirito coletivo que justificava e motivava o enfrentamento dos mitos inibidores. Com relação aos mitos inibidores podemos perceber que, tanto nos textos ideológicos do Estado Nacional quanto os diferentes textos que divulgavam a morte de Sayão, a natureza era vista como a grande força inibidora da grandeza nacional: "era o general de uma batalha terrível. Morreu em combate contra a floresta". No caso da construção da Rodovia Belém-Brasília, a mitificação do neobandeirismo acontecia, não mais por meio das lendas que apelavam para o sobrenatural, mas pelos desafios geográficos que inibiam a integração entre as regiões norte e sul do país. Um artigo publicado em 22 de janeiro de 1959 (Jornal Última Hora) chamava atenção dos que ainda não haviam aderido aos apelos do desenvolvimentismo, e afirmava que, a partir do gesto e exemplo de Bernardo Sayão muitos seriam contagiados. Ao criticar os opositores do desenvolvimentismo identificava e reforçava os novos mitos inibidores, desqualificando e fragilizando a oposição política da época:

A existência do plano, a sua concepção e execução, dependiam desse homem pioneiro, desbravador, poeta, idealista e de uma macheza sem par. Dou minha palavra que se os homens que fazem oposição injusta 
aos planos de Brasília acompanhassem o Engenheiro Sayão nas suas penetrações de helicóptero, jipe, trator ou a pé, terminariam por capitular. Nada resiste ao seu entusiasmo, à sua vontade de lutar e ganhar a partida. Ele sabia que o inimigo era a floresta. Se aqueles milhões de soldados (as árvores) fossem vencidos, os homens de terno branco (da oposição) não teriam outro jeito a não ser calar. O seu negócio era com a Natureza, a sua briga contra os elementos, mesmo porque ele sabia que a outra natureza (a dos homens) é mais fácil de vencer. Os outros elementos (os da política) mudam com o vento (JORNAL ÚLTIMA HORA, 1959: 63).

Os mitos da bandeira histórica eram reforçados na constituição simbólica dos mitos do novo bandeirismo. Porém, a distinção estava na identificação dos novos mitos motivadores. Na citação acima podemos perceber que o autor procura desqualificar as forças políticas da oposição como insuficientes para inibir o desbravamento. No inicio desse mesmo artigo afirmava que era "fácil sentir que nenhuma oposição, nenhum argumento justo ou injusto impedirá que este Governo fique como marco definitivo". Os novos mitos motivadores da ocupação situavam-se no universo da política, sobretudo, no que se referia aos programas desenvolvimentistas: "Dou minha palavra que se os homens que fazem oposição injusta aos planos de Brasília acompanhassem o Engenheiro Sayão [...], terminariam por capitular". Os mitos modernos que motivavam o deslocamento fundamentavam-se nos discursos da grandeza nacional, da territorialidade e da expansão de fronteiras, caracterizados nos programas desenvolvimentistas. A nova bandeira mantinha os velhos mitos da natureza (florestas, rios, igarapés, febres, etc) e substituía os referenciais dos velhos mitos motivadores (montanhas de ouro e esmeralda) pelo discurso do progresso e desenvolvimento nacional. É o que exemplificava o artigo publicado em 23 de janeiro de 1959 pelo jornal "O Globo" do Rio de Janeiro:

Uma árvore enorme cai e mata o bravo e alvissareiro Bernardo Sayão. É com árvores a guerra do Currupira quando falham a Boiuna, as febres $e$ os tresmalhamentos. Mas, a rodovia já perfurou a linha, e 
aquele imenso e largo corte na floresta não se fechará mais. O cimento esteriliza a fecundidade desumana da selva tropical; inutilmente os pássaros cúmplices deixarão cair sementes na faixa profanada. Por ali passarão as divisões blindadas do progresso, os caminhões de Manaus e de Belém a caminho do centro geo- econômico do país. [...] Quero ver o mundão de árvores arrancadas: mitos e totens zangando de raiva na sua impotência. Quero ver o Brasil derrotar o Currupira e tomar conta do que havia quase esquecido que the pertencia. Quero me vingar dos meus terrores no rio, do estrondo das terras caídas, da presença pressentida do inimigo invisível (PONGETTI, 1959:. 66).

No relato acima podemos perceber a manutenção dos mitos da bandeira histórica na caracterização do Currupira, protetor da floresta e seus aliados (Boiuna, febres, tresmalhamentos, as árvores e os pássaros cúmplices, dentre outros), "mitos e totens zangando de raiva na sua impotência". Os mitos vencedores, por sua vez, colocavam-se no enfrentamento à "presença pressentida do inimigo invisível" por meio das estradas que foram abertas. O sentido desenvolvimentista do mito vencedor assumia o domínio "do que havia quase esquecido que lhe pertencia", numa alusão ao renascimento da empreitada bandeirante no século XX, e a construção da rodovia (por onde "passarão as divisões blindadas do progresso") simbolizava essa política. Os textos, discursos, depoimentos e registros fotográficos apresentam instantes da vida pública de Bernardo Sayão que evidenciam o caráter animista do arquétipo bandeirante. Nessas imagens podemos identificar a forma como o mito da riqueza $e$ prosperidade - agora como o novo sentido nacional do progresso e desenvolvimento - suplantava os mitos inibidores da floresta. Esse novo referencial apresentava a "natureza vencida", destacando, assim, a coragem empreendida no desbravamento e no exorcismo dos temores naturais, ao retratar as derrubadas, as aberturas de estradas, as máquinas trabalhando na ocupação do espaço "hostil" da floresta, como sentido heróico do desbravador. Nos vários relatos fúnebres de Sayão, os oradores buscaram evidenciar o enfrentamento travado com a natureza e a tragédia que marcou o encerramento dessa empreitada, exemplificado na oração proferida pelo Presidente Juscelino Kubitschek, em que ele destacava o 
caráter heróico e o enfrentamento com a natureza:

Morre de pé, no meio das últimas resistências da floresta imensa, quando o termo dos seus árduos trabalhos estava à vista. Quem o feriu foi justamente uma dessas numerosas árvores que ele teve que abater para que o Brasil abrisse o seu mais difícil caminho [...] Caiu num golpe fatal, vibrado por toda selva, através de um dos seus gigantes vegetais. Foi uma vingança da natureza na pessoa desse bandeirante moderno, desse desbravador incomparável (KUBITSCHEK, 1959: 15$6)$.

O desbravador como categoria simbólica situava-se no contexto histórico em que a consciência ecológica era sobreposta pelo ideal desenvolvimentista. Portanto, a vingança da natureza, ao invés de desconsiderar ou atribuir uma carga negativa ao empreendimento, tornava a empreitada heroica. Em discurso proferido no Senado Federal em 22 de janeiro de 1959, o Senador Apolônio Salles, utilizando uma narrativa cheia de retóricas, considerou o trabalho de Sayão na abertura de estradas como uma "epopéia de proporções incalculáveis":

$\mathrm{Na}$ integração do seu programa de desenvolvimento do Brasil, explica-se, assim, o entusiasmo do Presidente Juscelino Kubitschek pela rodovia Belem- Brasilia.[...] Percorrendo-a sentir-se-á o viajante envolto numa aura de conquista. Não poderá ficar insensível à pressão do grandioso quem se disponha a palmilhar a rodovia pioneira. O murmúrio das florestas, a cantiga das águas barrentas dos rios caudalosos, o silêncio dos raros descampados, tudo se há de integrar no cenário da antevisão de uma tarefa imensurável reservada às gerações futuras amantes do Brasil (SALLES, 1959: 30-1).

O discurso do senador apresentava a relação entre o desenvolvimentismo e o desbravamento, exemplificada na construção da "rodovia pioneira", símbolo do "programa de desenvolvimento" e razão de 
entusiasmo. Uma sutil referência à natureza, evitando o confronto, diferente de outras narrativas, faz menção à convivência pacífica entre os elementos naturais e nova rodovia. Outra referência utilizada foi conceber $o$ desbravamento como ato político feito em nome da coletividade e nacionalidade ("reservada às gerações futuras amantes do Brasil"). Apesar de vários outros depoimentos terem destacado os atributos de Bernardo Sayão como construtor de estradas, a grande força simbólica que o qualificava como bandeirante deveu-se a tragédia que resultou em sua morte no canteiro da rodovia federal, que deram novos sentidos a sua empreitada. Considerando que o valor de uma imagem era medida pela extensão de sua aura imaginária (PITTA, 2005), podemos perceber como eventos convergem para si temáticas maiores que circulam no imaginário social. Assim, de construtor de estradas passava a representar a integração, o progresso e o desenvolvimento nacional. A força simbólica da morte de Sayão no canteiro de obras o qualificou, por meio dos novos discursos políticos em decorrência do seu falecimento, como um "bandeirante do século XX. Ao mesmo tempo, a percepção das questões ambientais nos discursos desenvolvimentista reforçava o enfrentamento, em que as forças da natureza apareciam como opositoras ao desenvolvimento e ao progresso nacional. Portanto, justificavam-se desmatamentos, devastações, destruições, entradas, aberturas e combates, pois esses elementos compunham um exército inimigo que carecia ser combatido em nome da grandeza nacional.

Os discursos da década de 1940 e 1950 nos chocam pela maneira pouco cerimoniosa em tratar os desmatamentos, os enfrentamentos, os largos cortes nas florestas, do cimento esterilizador da fecundidade da selva, do ataque aos animais (pássaros cúmplices da fecundidade florestal) feitos pelas divisões blindadas em nome do progresso. Palavras de ordem que não expressavam apenas a consciência de escritores, ideólogos, políticos e jornalistas, mas o imaginário social de uma geração que admitia regozijar-se em "ver o mundão de árvores arrancadas: mitos e totens zangando de raiva na sua impotência". O tom belicoso do enfrentamento com a natureza proclamava a vitória do desenvolvimento sobre o selvagem na morte de velhos mitos e temores que o mundo natural representava: "Quero ver o Brasil derrotar o Currupira e tomar conta do que havia quase esquecido que lhe pertencia. Quero me vingar dos meus terrores no rio, do estrondo das terras caídas, da presença pressentida do inimigo invisível".

Algumas narrativas que mostram a expansão e ocupação das regiões 
de fronteiras brasileiras basearam-se nas representações e mitos do destino bandeirante para caracterizar o ato heroico de desbravar, enfrentar as forças da "natureza hostil" e promover a fixação do homem e garantir o progresso e desenvolvimento das riquezas nacionais. Essa representação do desbravamento como ato heroico, herdeiro do destino histórico das bandeiras incorporava em suas narrativas elementos políticos diversos, mas que combinavam na valorização do sentido e do progresso nacional. Esse destino histórico bandeirante, apesar dos avanços percebidos nas agendas e legislações ambientais, persiste no imaginário bandeirante de ocupação de desbravamento e na consciência política da nação em marcha que considera que "todo brasileiro que abre caminhos novos é um bandeirante". 